\title{
DETERMINAN NIAT UNTUK MELAKUKAN WHISTLEBLOWING PADA PEMERINTAH DAERAH
}

\author{
Merri Agustin', Yesi Mutia Basri ${ }^{2}$, Edfan Darlis² \\ ${ }^{123}$ Jurusan Akuntansi, Fakultas Ekonomi dan Bisnis, Universitas Riau \\ Email :yesimutia@gmail.com
}

\begin{abstract}
This study aims to determine the factors that influence the intentions of government employees to do whistleblowing. This research examines Effect of personal cost of reporting, level of seriousness of fraud, organizational commitment and professional commitment on the intention to do whistleblowing. The population in this study were all staff / employees at OPD Kuantan Singingi. The sampling method used in this study was the purposive sampling and using the sample of 72 civil servants from 24 different $O P D$. The results of regression analysis show that personal cost affects the intention to do whistleblowing. 2) the level of seriousness of fraud affects the intention to do whistleblowing. 3) organizational commitment affects the intention to do whistleblowing. 4) professional commitment affects the intention to do whistleblowing. This research has a contribution in reducing fraud in government
\end{abstract}

Kata Kunci: Intention of Conducting Whistleblowing, Personal Cost of Reporting, The Level of Seriousness of Fraud, Organizational Commitment, Professional Commitment

\begin{abstract}
Abstrak
Penelitian ini bertujuan untuk menentukan beberapa faktor yang mempengaruhi niat pegawai pemerintah melakukan whistleblowing. Penelitian ini menguji Pengaruh biaya pribadi pelaporan tingkat keseriusan kecurangan, komitmen organisasi dan komitmen profesional terhadap niat untuk melakukan whistleblowing. Populasi dalam penelitian ini adalah semua staf / karyawan di OPD Kuantan Singingi. Metode pengambilan sampel yang digunakan dalam penelitian ini adalah purposive sampling dan menggunakan sampel 72 pegawai negeri sipil dari 24 OPD yang berbeda. Hasil analisis regresi menunjukkan bahwa biaya pribadi mempengaruhi niat melakukan whistleblowing. 2) tingkat keseriusan penipuan mempengaruhi niat melakukan whistleblowing. 3) komitmen organisasi mempengaruhi niat melakukan whistleblowing. 4) komitmen profesional
\end{abstract}

* Corresponding author's e-mail: yesimutia@gmail.com http://openjournal.unpam.ac.id/index.php/JABI 
mempengaruhi niat melakukan whistleblowing. Penelitian ini memiliki kontribusi dalam mengurangi kecurangan di pemerintahan

Kata Kunci: Niat Melakukan Pelaporan Pelanggaran, Biaya Pelaporan Pribadi, Tingkat Keseriusan Penipuan, Komitmen Organizatinal, Komitmen Profesional

\section{PENDAHULUAN}

Maraknya tindak kecurangan yang terungkap beberapa tahun belakangan ini baik di sektor publik maupun di sektor swasta mendapat perhatian yang serius dari masyarakat. Khususnya yang terjadi di sektor publik di Indonesia, tipologi fraud yang paling sensitif dan menjadi perhatian adalah Korupsi. Korupsi merupakan tindakan seseorang yang menyalahgunakan kepercayaan dalam suatu masalah atau organisasi untuk mendapatkan keuntungan (www.wikepedia.com). Tindakan korupsi ini terjadi karena beberapa faktor-faktor yang terjadi di dalam kalangan masyarakat. Faktor penyebab korupsi antara lain adalah faktor internal dan eksternal. Faktor internal merupakan sebuah sifat yang berasal dari diri kita sendiri seperti sifat tamak dan gaya hidup konsumtif, sedangkan faktor eksternal merupakan sifat yang berasal dari luar diri kita seperti faktor politik, faktor hukum, fakor ekonomi, dan faktor organisasi.

Berdasarkan Indeks Persepsi Korupsi (IPK) pada tahun 2017, Indonesia menempati urutan ke 90 dari 176 negara. Hal ini menunjukkan bahwa tingkat persepsi kasus-kasus kecurangan dan pelanggaran di Indonesia masih sangat tinggi. Dan salah satu kecurangan yang sering terjadi adalah korupsi. Korupsi selalu menimbulkan kerugian, untuk itu korupsi perlu diberantas. Seberapapun kecilnya dana yang dikorupsi, pemberantasan korupsi kecil sama strategisnya dengan pemberantasan korupsi besar (Diniastri, 2010). Bibit korupsi kecil jika dibiarkan dapat menjadi sebuah kebiasaan buruk yang berbuah korupsi besar. Untuk memberantas korupsi yang terjadi dalam suatu organisasi, tentu korupsi tersebut harus dideteksi terlebih dahulu. Salah satu alat yang efektif digunakan untuk mendeteksi korupsi adalah dengan memberdayakan Whistle-blowing. Partisipasi dalam sistem whistleblowing bisa menjadi respon untuk memberikan informasi tentang indikasi korupsi (Winardi, 2013).

Whistleblowing merupakan pelaporan yang dilakukan oleh anggota organisasi (aktif maupun non-aktif) mengenai pelanggaran, tindakan ilegal atau tidak bermoral kepada pihak didalam maupun diluar organisasi (Destriana, 2014). Sedangkan pihak yang mengungkapkan kecurangan atau yang melakukan whistleblowing disebut whistleblower. Pada dasarnya pelapor pelanggaran (whistleblower) adalah karyawan dari organisasi itu sendiri (pihak internal), akan tetapi tidak tertutup adanya pelapor dari pihak eksternal seperti pelanggan, pemasok, dan masyarakat (Sagara, 2013).

* Corresponding author's e-mail: yesimutia@gmail.com

http://openjournal.unpam.ac.id/index.php/JABI 
Di Kabupaten Kuantan Singingi, Riau kasus witleblowing terjadi pada mantan bupati Kuantan Singingi dilaporkan ke KPK dan ICW terkait mark up anggaran. Pada kasus ini yang menjadi whistleblower adalah Rezaludin Bakar selaku aktifis anti korupsi dan advokat senior. Whistleblower mengatakan dirinya mengambil langkah untuk melayangkan laporan kepada dua lembaga tersebut, mengingat banyaknya laporan didaerah yang hingga saat ini masih belum diselesaikan penegak hukum.(www.bualbual.com).

Berdasarkan uraian di atas, maka dapat disimpulkan bahwa whistleblowing sangat penting dilakukan dalam hal pengungkapakan atas pelanggaran-pelanggaran yang terjadi. Terkait pemahaman tentang efektivitas whistleblowing tersebut kemudian memicu berbagai organisasi untuk menerapkan hotline whistleblowing system untuk mendeteksi kecurangan melalui berbagai sarana komunikasi seperti pada layanan pengaduan telepon atau jaringan internet.

\section{TINJAUAN PUSTAKA}

Whistleblowing system merupakan sistem pelaporan pelanggaran yang masih tergolong baru diterapkan di Indonesia. Dalam rangka mendorong terciptanya GCG (Good Corporate Governance) dan memberikan manfaat bagi peningkatan kualitas pelaksanaan GCG di Indonesia maka KNKG (Komite Nasional Kebijakan Governance) menerbitkan Pedoman Sistem Pelaporan Pelanggaran (SPP) atau Whistleblowing System (WBS) pada tahun 2008 yang dapat digunakan oleh perusahaan untuk mengembangkan sistem manual pelaporan pelanggaran. Pedoman ini dibentuk karena terdorong hasil survei sebuah lembaga internasional yaitu Institute of Bussiness Ethics pada tahun 2007. Hasil survei tersebut menyimpulkan bahwa satu dari empat orang kayawan di dalam perusahaan mengetahui adanya pelangaran dan lebih dari separuh keseluruhan karyawan lebih memilih diam dan membiarkan pelanggaran tersebut terus terjadi (KNKG, 2008).

Personal cost merupakan faktor yang dianggap berpengaruh terhadap niat seseorang melakukan whistleblowing. Personal cost of reporting adalah pandangan pegawai terhadap risiko pembalasan/ balas dendam atau sanksi dari anggota organisasi, yang dapat mengurangi minat pegawai untuk melaporkan wrongdoing (Schutlz et al., 1993). Anggota organisasi yang dimaksud dapat saja berasal dari manajemen, atasan, atau rekan kerja. Beberapa pembalasan dapat terjadi dalam bentuk tidak berwujud (intangible), misalnya penilaian kinerja yang tidak seimbang, hambatan kenaikan gaji, pemutusan kontrak kerja, atau dipindahkan ke posisi yang tidak diinginkan (Curtis, 2006). Semakin besar persepsi personal cost seseorang maka akan semakin berkurang minat orang tersebut untuk melakukan tindakan whistle-blowing. Penelitian oleh Rifki (2018), menyatakan bahwa Personal cost of reporting berpengaruh terhadap whistleblowing internal. Sedangkan penelitian yang dilakukan oleh Bagustianto (2015) menyebutkan bahwa

* Corresponding author's e-mail: yesimutia@gmail.com http://openjournal.unpam.ac.id/index.php/JABI 
Jurnal Akuntansi Berkelanjutan Indonesia - Vol. 3, No. 3, Sep 2020 - Agustin, Basri \& Darlis

Personal cost of reporting berpengaruh negatif terhadap niat melakukan Whistleblowing.

Miceli dan Near (1985) menyatakan bahwa tingkat keseriusan kecurangan dapat mempengaruhi niat seseorang melakukan tindakan whistle-blowing. Tingkat keseriusan kecurangan adalah ukuran besar keseriusan pelanggaran yang dapat merugikan organisasi. Anggota organisasi yang mengamati adanya dugaan wrongdoing/kecurangan akan lebih mungkin untuk melakukan whistleblowing jika wrongdoing atau kecurangan tesebut serius. Organisasi akan terkena dampak kerugian yang lebih besar dari wrongdoing yang lebih serius dibandingkan dari wrongdoing yang kurang serius (Winardi, 2013). Persepsi tiap anggota organisasi terhadap tingkat keseriusan kecurangan dapat saja berbeda antara satu dengan yang lainnya. Pembentuk persepsi tingkat keseriusan kecurangan selain berkaitan dengan besaran nilai kecurangan, juga tidak dapat dipisahkan dari jenis kecurangan yang terjadi. Hasil penelitian yang menyatakan tingkat keseriusan kecurangan tidak berpengaruh terhadap niat melakukan whistleblowing ditemukan pada penelitian yang dilakukan oleh Odiatma (2017) tentang Pengaruh Personal Cost of Reporting, Status Wrong Doer, dan Tingkat Keseriusan Kesalahan terhadap Whistleblowing Intention. Dan hasil yang berbeda yang dilakukan oleh Resi Marliza (2017) yang menyatakan bahwa tingkat keseriusan kecurangan berpengaruh positif terhadap niat melakukan whistleblowing.

Faktor yang juga mempengaruhi mempengaruhi niat seseorang melakukan whistle-blowing adalah komitmen organisasi. Komitmen organisasi adalah kekuatan relatif identifikasi dan keterlibatan individu dalam organisasi tertentu yang dapat ditandai dengan tiga faktor terkait yaitu: pertama, keyakinan yang kuat dan penerimaan terhadap tujuan dan nilai-nilai organisasi; kedua, kesediaan untuk mengerahkan usaha yang cukup atas nama organisasi; dan ketiga, keinginan yang kuat untuk mempertahankan keanggotaan dalam organisasi (Mowday et al. 1979). Hasil penelitian Setiawati dan Sari (2016) menyatakan bahwa komitmen organisasi berpengaruh terhadap niat whistle-blowing pada anggota dari National Association of Accountant (NAA). Hasil berbeda yang didapat oleh Septianti (2013) menyatakakan bahwa komitmen organisasi tidak berpengaruh terhadap niat melakukan whistleblowing.

Faktor selanjutnya yang mempengaruhi niat seseorang melakukan tindakan whistleblowing adalah komitmen profesional. Komitmen profesional adalah tingkat loyalitas individu pada profesinya seperti yang dipersepsikan oleh individu tersebut. Shaub et al (1993) menekankan perlunya untuk belajar komitmen profesional karena karier seseorang merupakan bagian utama dari hidupnya dan komitmen profesional mempunyai implikasi penting di tingkat individu dan organisasi. Tingkat komitmen profesional mungkin merupakan refleksi hubungan staf atau karyawan dengan lingkungan industri profesional. Berkomitmen terhadap profesi berarti berkeyakinan bahwa profesi yang dilakukan memiliki dan memberikan hal yang baik bagi diri seseorang. Hal ini pun muncul berdasarkan pertimbangan seseorang atas apa yang dinilainya baik dan benar. Penelitian

* Corresponding author's e-mail: yesimutia@gmail.com

http://openjournal.unpam.ac.id/index.php/JABI 
sebelumnya oleh Amalia (2018) menyatakan bahwa komitmen profesional berpengaruh terhadap whistleblowing, sedangkan hasil berbeda diperoleh oleh Gandamihar dkk (2016) yang menyatakan bahwa komitmen profesional tidak berpengaruh terhadap niat melakukan whistleblowing.

Berdasarkan uraian di atas, masih terlihat adanya ketidak konsistenan hasil penelitian. Oleh sebab itu penelitian mengenai wishtleblowing masih menarik untuk dilakukan. Penelitian ini mengembangkan penelitian dilakukan oleh Bagustianto dan Nurkholis (2015) yang meneliti Faktor-Faktor yang Mempengaruhi Minat Pegawai Negeri Sipil (PNS). Untuk Melakukan Tindakan Whistleblowing pada PNS BPK RI. Penelitian ini penambahan Komitmen Profesional sebagai salah satu faktor yang mempengaruhi niat seseorang untuk melakukan wihistleblowing. Sebagaimana yang dilakukan Amalia (2018) menemukan bahwa komitmen profesional dapat mempengaruhi seseorang melakukan tindakan withleblowing. Penelitian ini dilakukan pada OPD di Kabupaten Kuantan Singingi didasrkan pada maraknya tindak kecurangan yang terungkap belakangan ini di OPD Kuantan Singingi sehingga mendapat perhatian yang serius dari publik. Penelitian mengenai whistleblowing. telah banyak dilakukan di Indonesia maupun luar negeri dengan responden yang berbeda maupun responden yang sama. Namun dengan objek penelitian dan variabel penelitian yang berbeda tentu akan menghasil hasil penelitian yang berbeda juga.

Berdasarkan uraian diatas penelitian ini bertujuan untuk menguji dan menganalisis pengaruh Personal Cost Of Reporting, Tingkat Keseriusan Kercurangan, Komitmen Organisasi dan Komitmen Profesional terhadap Niat Melakukan whistleblowing. Penelitian ini memiliki kontribusi secara praktik dan secara teoritis. Secara teoritis penelitian ini menjadi referensi bagi penelitian selanjutnya dan secara praktek memiliki kontribusi dalam mengurangi terjadinya kecurangan pada pemerintah.

\section{METODE PENELITIAN}

\section{Populasi dan Sampel}

Populasi dalam penelitian ini adalah seluruh staff/pegawai pada OPD Kuantan Singingi. Sampel yang dipilih dari populasi dianggap mewakili keberadaan populasi. Adapun teknik pengambilan sampel menggunakan metode purposif sampling, yaitu sampel dipilih berdasarkan pertimbangan-pertimbangan tertentu sesuai dengan tujuan penelitian. Sampel dipilih dari sub populasi sifat sesuai dengan sifat populasi yang sudah diketahui sebelumnya.

Adapun kriteria pengambilan sampel dalam penelitian ini adalah:

1. Staff/pegawai tersebut yang tidak menduduki jabatan tertentu.

2. Masa kerjaStaff/pegawai minimal 3 tahun di OPD yang sama.

Alasan pemilihan sampel dengan kriteria tersebut bertujuan untuk menghindari penyimpangan yang disebabkan oleh perbedaan yang ekstrim, dan

* Corresponding author's e-mail: yesimutia@gmail.com

http://openjournal.unpam.ac.id/index.php/JABI 
agar lebih valid dalam pengukurannya dan ingin mengetahui sejauh mana tingkat partisipasi staff/pegawai di Organisasi Perangkat Daerah (OPD) Kuantan Singingi dalam melakukan Internal Whistleblowing, dan selain itu alasan mengapa dipilihnya dengan kriteria tersebut karena:

1. Apabila sampel menduduki jabatan yang paling tinggi karena tidak ada seorang dengan jabatan yang lebih tinggi untuk menerima pengaduannya, maka ia akan melakukan tindakan whistleblowing eksternal, sedangkan didalam penelitian ini adalah tentang tindakan whistleblowing internal (Husnianti, 2016).

2. Masa kerja merupakan komponen yang terdiri dari usia, lama kerja, dan golongan kepangkatan. Hasil penelitian Seniati (2016) menunjukkan hasil masa kerja dan trait (sifat) kepribadian memiliki pengaruh yang lebih besar terhadap komitmen dibandingkan kepuasan kerja.

\section{Teknik Pengumpulan Data}

Dalam penelitian ini teknik pengumpulan data primer dilakukan dengan metode survei yaitu metode pengumpulan data primer yang menggunakan pertanyaan tertulis. Metode survei yang digunakan adalah dengan cara menyebarkan kuesioner kepada responden dalam bentuk pertanyaan tertulis. Masing-masing OPD (Satuan Kerja Perangkat Daerah) diberikan kuesioner dengan jangka waktu pengembalian 2 minggu terhitung sejak kuesioner diterima oleh responden. Pertanyaan-pertanyaan dalam kuesioner dibuat menggunakan skala 1 sampai dengan 5 untuk mendapatkan rentang jawaban sangat setuju sampai dengan jawaban sangat tidak setuju dengan memberi tanda cek $(\sqrt{ })$ atau tanda silang $(\times)$ pada kolom yang dipilih. Kuesioner dengan bentuk ini lebih menarik responden karena kemudahannya dalam memberi jawaban dan juga waktu yang digunakan untuk menjawab akan lebih singkat.

\section{Matriks Definisi Operasional dan Pengukuran Variabel}

\begin{tabular}{llll}
\hline \multicolumn{1}{c}{ Jenis Variabel } & \multicolumn{1}{c}{ Definisi } & \multicolumn{1}{c}{ Indikator } & \multicolumn{1}{c}{ Skala } \\
\hline Niat Melakukan & Niat melakukan & Keinginan untuk & Skala \\
Whisteblowing (Y) & whistleblowing mengacu pada & melaporkan suatu & Ordinal \\
& kemungkinan individu yang & pelanggaran dinilai & \\
benar-benar terlibat dalam & dengan mengasumsikan & \\
& perilaku whistleblowing dan & responden sebagai & \\
berkeinginan untuk & karyawan yang & \\
& melakukan whistleblowing. & menyadari adanya & \\
& Menurut Near dan Miceli & tindakan-tindakan yang & \\
& (1985), intensi seseorang & mencurigakan dalam & \\
& dalam melakukan tindakan & kasus-kasus tersebut. & \\
& whistleblowing merupakan & & \\
& tindakan yang mungkin & & \\
& dilakukan individu untuk & & \\
& melaporkan pelanggaran baik & & \\
& secara internal maupun secara & & \\
& eksternal. & & \\
\hline
\end{tabular}

* Corresponding author's e-mail: yesimutia@gmail.com http://openjournal.unpam.ac.id/index.php/JABI 


\begin{tabular}{ll}
\hline Personal Cost of & Personal Cost of Reporting \\
Reporting (X1) & didefinisikan sebagai \\
pandangan pegawai terhadap & risiko pembalasan, balas \\
& dendam atau sanksi dari \\
& anggota organisasi, yang \\
& dapat mengurangi minat \\
& pegawai negeri untuk \\
& melaporkan kecurangan. \\
& Personal Cost merupakan \\
& salah satu alasan utama yang \\
& menyebabkan seseorang \\
& tidak ingin melaporkan \\
& dugaan pelanggaran karena \\
& mereka meyakini bahwa \\
& laporan mereka tidak akan \\
& ditindaklanjuti, mereka akan \\
& mengalami retaliasi, atau \\
& manajemen tidak akan \\
& melindungi mereka dari \\
ancaman retaliasi, khususnya & dalam jenis pelanggaran \\
yang melibatkan para \\
manajer (Septianti, 2013: \\
1067).
\end{tabular}

\begin{tabular}{|c|c|c|c|}
\hline $\begin{array}{l}\text { Tingkat Keseriusan } \\
\text { Kecurangan (X2) }\end{array}$ & $\begin{array}{l}\text { Tingkat Keseriusan } \\
\text { Kecurangan adalah ukuran } \\
\text { besar keseriusan pelanggaran } \\
\text { yang dapat merugikan } \\
\text { organisasi. Anggota } \\
\text { organisasi yang mengamati } \\
\text { adanya dugaan pelanggaran } \\
\text { akan lebih mungkin untuk } \\
\text { melakukan whistleblowing } \\
\text { jika pelanggaran tersebut } \\
\text { serius (Miceli and Near, } \\
\text { 1985). }\end{array}$ & $\begin{array}{l}\text { Kasus mengenai } \\
\text { penyalahgunaan asset } \\
\text { Kasus mengenai } \\
\text { korupsi } \\
\text { Kasus mengenai fraud }\end{array}$ & $\begin{array}{l}\text { Skala } \\
\text { Ordinal }\end{array}$ \\
\hline $\begin{array}{l}\text { Komitmen } \\
\text { Organisasi (X3) }\end{array}$ & $\begin{array}{l}\text { Robbins dan Judge, } \\
\text { (2008:100) komitmen } \\
\text { organisasi adalah tingkat } \\
\text { sampai mana seorang } \\
\text { karyawan memihak sebuah } \\
\text { organisasi serta tujuan-tujuan } \\
\text { dan keinginannya untuk } \\
\text { mempertahankan } \\
\text { keanggotaan dalam organisasi } \\
\text { tersebut. Komitmen pada } \\
\text { organisasi yang tinggi dapat }\end{array}$ & $\begin{array}{l}\text { Berusaha dan bekerja } \\
\text { lebih keras untuk } \\
\text { membantu OPD } \\
\text { mencapai tujuannya } \\
\text { Menyampaikan kepada } \\
\text { teman bahwa OPD } \\
\text { adalah organisasi yang } \\
\text { baik untuk bekerja }\end{array}$ & $\begin{array}{l}\text { Skala } \\
\text { Ordinal }\end{array}$ \\
\hline
\end{tabular}

* Corresponding author's e-mail: yesimutia@gmail.com http://openjournal.unpam.ac.id/index.php/JABI 


\begin{tabular}{|c|c|c|c|}
\hline & $\begin{array}{l}\text { diartikan bahwa pemihakan } \\
\text { karyawan (loyalitas) pada } \\
\text { organisasi yang } \\
\text { memperkerjakannya adalah } \\
\text { tinggi. } \\
\text { Karyawan yang berkomitmen } \\
\text { terhadap organisasi akan } \\
\text { menunjukkan sikap dan } \\
\text { perilaku positif terhadap } \\
\text { lembaganya, karyawan akan } \\
\text { memiliki jiwa untuk tetap } \\
\text { membela organisasinya, } \\
\text { berusaha meningkatkan } \\
\text { prestasi, dan memiliki } \\
\text { keyakinan yang pasti untuk } \\
\text { mewujudkan tujuan } \\
\text { organisasi (Kuryanto, 2011). }\end{array}$ & $\begin{array}{l}\text { Loyalitas pada OPD } \\
\text { tidak tinggi } \\
\text { Rela menerima semua } \\
\text { jenis penugasan agar } \\
\text { tetap bekerja di OPD }\end{array}$ & \\
\hline $\begin{array}{l}\text { Komitmen } \\
\text { Profesional (X4) }\end{array}$ & $\begin{array}{l}\text { Aranya et al (1981: 272) } \\
\text { mendefinisikan komitmen } \\
\text { professional sebagai kekuatan } \\
\text { relatif dari indentifikasi } \\
\text { individual dengan keterlibatan } \\
\text { dalam suatu profesi dan } \\
\text { termasuk keyakinan dan } \\
\text { penerimaan tujuan-tujuan dan } \\
\text { nilai-nilai profesi, kemauan } \\
\text { untuk berupaya sekuat tenaga } \\
\text { demi organisasi, dan } \\
\text { keinginan menjaga } \\
\text { keanggotaan dari suatu } \\
\text { profesi. }\end{array}$ & $\begin{array}{l}\text { Dedikasi terhadap } \\
\text { profesi } \\
\text { Tanggung jawab } \\
\text { professional } \\
\text { Kebutuhan untuk } \\
\text { mandiri } \\
\text { Percaya pada } \\
\text { pengaturan sendiri } \\
\text { Perkumpulan profesi }\end{array}$ & $\begin{array}{l}\text { Skala } \\
\text { Likert }\end{array}$ \\
\hline
\end{tabular}

Sumber : Data Olahan (2020)

\section{HASIL DAN PEMBAHASAN}

Data yang digunakan dalam penelitian ini adalah data primer. Data ini diperoleh dari jawaban responden atas pertanyaan-pertanyaan dalam kuesioner. Responden dalam penelitian ini OPD (OrganisasiPerangkat Daerah) Kabupaten Kuantan Singingi. Dalam proses pendistribusian kuesioner, peneliti secara langsung mengantarkan kuesioner ke seluruh OPD yang bersangkutan di Kabupaten Kuantan Singing. Kuesioner penelitian ini mulai disebar dan terkumpul pada Januari 2020. Adapun tingkat pengembalian kuesioner dapat dilihat pada tabel 1 berikut ini :

* Corresponding author's e-mail: yesimutia@gmail.com http://openjournal.unpam.ac.id/index.php/JABI 
Jurnal Akuntansi Berkelanjutan Indonesia - Vol. 3, No. 3, Sep 2020 - Agustin, Basri \& Darlis

Tabel 1 Tingkat Pengembalian Kuesioner

\begin{tabular}{lcr}
\hline \multicolumn{1}{c}{ Keterangan } & Jumlah & Persentase (\%) \\
\hline Kuesioner yang dikirim & 72 & $100 \%$ \\
Kuesioner yang kembali & 72 & $100 \%$ \\
Kuesioner yang tidak mendapatkan respon & 0 & $0 \%$ \\
Kuesioner yang dapat diolah & 72 & $100 \%$ \\
\hline
\end{tabular}

Sumber : Data Olahan (2020)

Karakteristik yang diteliti meliputi jenis kelamin, umur, dan tingkat pendidikan responden. Ringkasan mengenai karakteristik responden dapat dilihat pada tabel 2 sebagai berikut :

Tabel 2 Karakteristik Responden Penelitian

\begin{tabular}{ccr}
\hline \multicolumn{1}{c}{ Keterangan } & Frekuensi & Persentasi \\
\cline { 1 - 2 } Jenis kelamin : & & \\
a. Laki-laki & 43 & $59,72 \%$ \\
b. Perempuan & 29 & $40,28 \%$ \\
\hline Jumlah & 72 & $100 \%$ \\
\hline Pendidikan terakhir: & 14 & $19,44 \%$ \\
a. Lainnya & 11 & $15,28 \%$ \\
b. D3 & 38 & $52,78 \%$ \\
c. S1 & 9 & $12,5 \%$ \\
d. S2 & 72 & $100 \%$ \\
\hline Jumlah & & \\
\hline Usia : & 31 & 43,06 \\
a. 21-30 Tahun & 23 & 31,94 \\
b. 31-40 Tahun & 14 & 19,44 \\
c. 41-50 Tahun & 4 & 5,56 \\
d. >50 Tahun & 72 & $100 \%$ \\
\hline Jumlah & & \\
\hline Masa kerja : & 63 & $87,5 \%$ \\
a. 1-10 tahun & 8 & $11,11 \%$ \\
b. 10-20 tahun & 1 & $1,39 \%$ \\
c. >20 tahun & 72 & \\
\hline Jumlah & & \\
Sumber : Data Olahan 2020 & &
\end{tabular}

\section{Hasil Statistik Deskriptif}

Statistik deskriptif memberikan gambaran atau deskripsi suatu data yang dilihat dari nilai rata-rata (mean), standar deviasi, varian, maksimum, minimum, sum, range, kurtosis dan skewness (kemencengan distribusi) (Ghozali, 2011:19). Dalam tabel ini menyajikan kisaran teoritis yang merupakan kisaran atas bobot jawaban yang secara teoritis didesain dalam kuesioner dan kisaran sesungguhnya nilai terendah sampai nilai tertinggi atas jawaban responden yang sesungguhnya. Serta rata-rata dan standard deviasinya. Adapun instrumen yang digunakan dalam penelitian in iterdiri dari 5 pengukur variabel. Personal Cost menggunakan 3 item

* Corresponding author's e-mail: yesimutia@gmail.com http://openjournal.unpam.ac.id/index.php/JABI 
Jurnal Akuntansi Berkelanjutan Indonesia - Vol. 3, No. 3, Sep 2020 - Agustin, Basri \& Darlis

pernyataan. Intensitas Moral menggunakan 5 item pernyataan. Komitmen organisasi menggunakan 15 item pernyataan. Tingkat Keseriusan Kecurangan menggunakan 15 item pernyataan. Serta intense untuk melakukan Whistleblowing menggunakan 15 pernyataan.

Gambaran mengenai variabel-variabel penelitian tersebut disajikan dalam table Descriptive Statistics berikut ini :

Tabel 3 Hasil Statistik Deskriptif

Descriptive Statistics

\begin{tabular}{lrrrrr}
\hline & \multicolumn{1}{c}{ N } & \multicolumn{2}{c}{ Minimum } \\
& Statistic & \multicolumn{1}{c}{ Statistic } & $\begin{array}{c}\text { Maximum } \\
\text { Statistic }\end{array}$ & $\begin{array}{c}\text { Mean } \\
\text { Statistic }\end{array}$ & $\begin{array}{c}\text { Std. Deviation } \\
\text { Statistic }\end{array}$ \\
\hline Personal Cost & 72 & 9 & 15 & 12.37 & 1.578 \\
Tingkat Keseriusan & 72 & 24 & 30 & 26.28 & 1.672 \\
Kecurangan & 72 & 60 & 75 & 67.14 & 4.043 \\
Komitmen Organisasi & 72 & 28 & 35 & 31.86 & 1.938 \\
Komitmen Profesional & 72 & 60 & 75 & 67.18 & 3.735 \\
Intensi & 72 & & & & \\
Whistleblowing & 72 & & & &
\end{tabular}

\section{Hasil Uji Kualitas Data}

Kualitas data yang dihasilkan dari penggunaan instrument penelitian dapat dievaluasi melalui Uji Validitas dan Uji Reliabillitas.

\section{Hasil Uji Validitas}

Uji validitas dilakukan dengan membandingkan nilai $r_{\text {hitung }}$ dengan $r_{\text {tabel }}$ untuk degree of freedom $(\mathrm{df})=\mathrm{n}-2$, dimana $\mathrm{n}$ adalah jumlah sampel. Pada penelitian ini diperoleh $\mathrm{df}=72-2=70$. Nilai $\mathrm{r}$ tabel dengan derajat bebas (df) 70 adalah sebesar 0,231

Untuk pengujian variable personal cost, tingkat keseriusan kecurangan, komitmen organisasi, dan komitmen professional, hasil dari uji validitas dapat disajikan sebagai berikut :

\begin{tabular}{lllll}
\hline Variabel & Pernyataan & r Hitung & r Tabel & Kesimpulan \\
\hline Personal Cost Of & PC1 & 0,869 & 0,231 & Valid \\
Reporting & KO2 & 0,848 & 0,231 & Valid \\
& KO3 & 0,890 & 0,231 & Valid \\
\hline Tingkat Keseriusan & TKK1 & 0,614 & 0,231 & Valid \\
Kecurangan & TKK2 & 0,788 & 0,231 & Valid \\
& TKK3 & 0,800 & 0,231 & Valid \\
& TKK4 & 0,800 & 0,231 & Valid \\
& TKK5 & 0,645 & 0,231 & Valid \\
& TKK6 & 0,468 & 0,231 & Valid \\
\hline
\end{tabular}

* Corresponding author's e-mail: yesimutia@gmail.com http://openjournal.unpam.ac.id/index.php/JABI 
Jurnal Akuntansi Berkelanjutan Indonesia - Vol. 3, No. 3, Sep 2020 - Agustin, Basri \& Darlis

\begin{tabular}{|c|c|c|c|c|}
\hline Komitmen & KO1 & 0,372 & 0,231 & Valid \\
\hline \multirow[t]{14}{*}{ Organisasi } & $\mathrm{KO} 2$ & 0,615 & 0,231 & Valid \\
\hline & KO3 & 0,548 & 0,231 & Valid \\
\hline & $\mathrm{KO} 4$ & 0,680 & 0,231 & Valid \\
\hline & KO5 & 0,707 & 0,231 & Valid \\
\hline & KO6 & 0,707 & 0,231 & Valid \\
\hline & $\mathrm{KO} 7$ & 0,704 & 0,231 & Valid \\
\hline & KO8 & 0,729 & 0,231 & Valid \\
\hline & KO9 & 0,576 & 0,231 & Valid \\
\hline & KO10 & 0,719 & 0,231 & Valid \\
\hline & KO11 & 0,756 & 0,231 & Valid \\
\hline & KO12 & 0,501 & 0,231 & Valid \\
\hline & KO13 & 0,468 & 0,231 & Valid \\
\hline & KO14 & 0,429 & 0,231 & Valid \\
\hline & KO15 & 0,411 & 0,231 & Valid \\
\hline Komitmen & KP1 & 0,461 & 0,231 & Valid \\
\hline \multirow[t]{6}{*}{ Profesional } & KP2 & 0,640 & 0,231 & Valid \\
\hline & KP3 & 0,783 & 0,231 & Valid \\
\hline & KP4 & 0,823 & 0,231 & Valid \\
\hline & KP5 & 0,818 & 0,231 & Valid \\
\hline & KP6 & 0,730 & 0,231 & Valid \\
\hline & KP7 & 0,549 & 0,231 & Valid \\
\hline Niat Melakukan & IW1 & 0,563 & 0,231 & Valid \\
\hline \multirow[t]{14}{*}{ Whistleblowing } & IW2 & 0,582 & 0,231 & Valid \\
\hline & IW3 & 0,625 & 0,231 & Valid \\
\hline & IW4 & 0,508 & 0,231 & Valid \\
\hline & IW5 & 0,676 & 0,231 & Valid \\
\hline & IW6 & 0,688 & 0,231 & Valid \\
\hline & IW7 & 0,535 & 0,231 & Valid \\
\hline & IW8 & 0,318 & 0,231 & Valid \\
\hline & IW9 & 0,377 & 0,231 & Valid \\
\hline & IW10 & 0,644 & 0,231 & Valid \\
\hline & IW11 & 0,613 & 0,231 & Valid \\
\hline & IW12 & 0,376 & 0,231 & Valid \\
\hline & IW13 & 0,245 & 0,231 & Valid \\
\hline & IW14 & 0,364 & 0,231 & Valid \\
\hline & IW15 & 0,508 & 0,231 & Valid \\
\hline
\end{tabular}

Sumber : Data Olahan 2020

Dilihat dari Tabel, diketahui bahwa nilai $r_{\text {hitung }}>r_{\text {tabel }}$ sehingga semua item pertanyaan untuk variable Intensi Whistleblowing ini dapat dikatakan valid.

\section{Hasil Uji Reliabilitas}

Hasil uji reliabilitas disajikan pada table 9 berikut ini :

Tabel 9 Hasil Pengujian Reliabilitas

\begin{tabular}{lllll}
\hline \multirow{2}{*}{ NO } & \multirow{2}{*}{ Instrument Variabel Penelitian } & $\begin{array}{l}\text { Cronbach's } \\
\text { Alpha }\end{array}$ & $\begin{array}{l}\text { Nilai } \\
\text { Kritis }\end{array}$ & \multirow{2}{*}{ Kesimpulan } \\
\hline 1 & Personal Cost (X1) & 0.838 & 0,6 & Reliabel \\
2 & Tingkat Keseriusan Kecurangan (X2) & 0,785 & 0,6 & Reliabel
\end{tabular}

* Corresponding author's e-mail: yesimutia@gmail.com http://openjournal.unpam.ac.id/index.php/JABI 


\begin{tabular}{lllll}
3 & Komitmen Organisasi (X3) & 0.873 & 0,6 & Reliabel \\
4 & KomitmenProfesional (X4) & 0.824 & 0,6 & Reliabel \\
5 & Intensi Whistleblowing (Y) & 0,790 & 0,6 & Reliabel \\
\hline
\end{tabular}

Sumber : Data Olahan 2020

Berdasarkan hasil uji validitas dan reliabilitas diatas terlihat bahwa seluruh instrument pernyataan yang digunakan untuk mengukur keseluruhan variabel yang diteliti dalam penelitian ini dinyatakan valid dan reliable, hal ini terlihat dari nilai Cronbach's Alpha seluruh variabel yang diteliti lebih besar dari 0.60. sehingga data yang dihasilkan dari instrument pernyataan dalam penelitian ini berkualitas dan layak untuk dianalisis lebih lanjut.

\section{Teknik Analisis Regresi Linear Berganda}

Metode yang digunakan dalam penelitian ini adalah regresi linear berganda. (Santoso,2014). Model ini digunakan untuk memperoleh gambaran menyeluruh mengenai pengaruh variabel bebas yaitu personal cost, tingkat keseriusan kecurangan, komitmen organisasi, komitmen professional terhadap variabel terikat yaitu intense whistleblowing. Analisis ini dilakukan dengan menggunakan bantuan program komputer statistical package for social science (SPSS) versi 23.0 for windows. Adapun Rumus regresi yang digunakan adalah :

$$
\mathrm{Y}=\alpha+\beta 1 \mathrm{X} 1+\beta 2 \mathrm{X} 2+\beta 3 \mathrm{X} 3+\beta 4 \mathrm{X} 4+\mathrm{e}
$$

\section{Hasil Uji Koefisien Determinasi $\left(\mathbf{R}^{2}\right)$}

Berdasarkan proses pengolahan data yang dilakukan maka diperoleh hasil pengujian koefisien determinasi sebagai berikut :

Tabel 13 Hasil Uji Koefisien Determinasi $\left(\mathrm{R}^{2}\right)$

\begin{tabular}{ccccc}
\hline Model & $\mathrm{R}$ & $\mathrm{R}$ Square & $\begin{array}{c}\text { Adjusted } \mathrm{R} \\
\text { Square }\end{array}$ & Std. Error of the Estimate \\
\hline 1 & 0.469 & 0.220 & 0.174 & 3.395 \\
\hline Sumber : Data Olahan 2020 & & &
\end{tabular}

Sumber : Data Olahan 2020

Nilai R square sebesar 0.220. artinya adalah bahwa sumbangan pengaruh variable independen terhadap variable dependen sebesar 22,0\% sedangkan sisanya sebesar 78,0\% dipengaruhi oleh variabel lain yang tidak dimasukkan dalam model ini.

* Corresponding author's e-mail: yesimutia@gmail.com http://openjournal.unpam.ac.id/index.php/JABI 


\section{HASIL PENGUJIAN HIPOTESIS DAN PEMBAHASAN}

\section{Hasil Pengujian Hipotesis 1 :}

Tabel 4.14 Hasil Regresi Parsial Hipotesis Pertama

\begin{tabular}{lllll}
\hline Variabel Independen & $\mathrm{t}_{\text {hitung }}$ & $\mathrm{t}_{\text {tabel }}$ & $\mathrm{Sig}$ & Keterangan \\
\hline Personal Cost & 2.255 & 1.996 & 0.027 & Berpengaruh \\
\hline
\end{tabular}

Sumber : Data Olahan 2020

Dari hasil pengujian, dapat dilihat bahwa $t_{\text {hitung }}>\mathrm{t}_{\text {tabel }}$ yaitu 2.255> 1.996 dan sig $\mathrm{t}(0.027)<0.05$ dengan demikian $\mathrm{H}_{01}$ ditolak dan Ha1 diterima. Maka dapat disimpulkan bahwa Personal Cost berpengaruh terhadap niat melakukan whistleblowing. Personal cost of reporting menunjukan adanya pandangan pegawai terhadap risiko pembalasan/ balas dendam atau sanksi dari anggota organisasi, yang dapat mengurangi minat pegawai untuk melaporkan wrongdoing (Schutlz et al., 1993). Ini dapat membuktikan bahwa pegawai organisasi perangkat daerah (OPD) di Kabupaten Kuantan Singingi akan takut untuk melaporkan kecurangan karena adanya tindak laku balas dendam yang akan didapat. Organisasi akan berdampak buruk atas tindak kecurangan yang lebih serius daripada kecurangan yang kurang serius. Apabila pegawai melihat adanya dugaan kecurangan yang berdampak buruk atas organisasinya, maka akan tumbuh niat untuk melakukan whistleblowing. Namun pandangan tiap anggota organisasi terhadap tingkat keseriusan kecurangan dapat saja berbeda antara satu dengan yang lainnya. Maka dapat disimpulkan bahwa semakin serius kecurangan yang terjadi dan dapat merugikan organisasi maka semakin tinggi pula seseorang untuk melaporkan kecurangan tersebut. Hasil penelitian ini mendukung Penelitian Rifki (2018) menyatakan bahwa Personal cost of reporting berpengaruh terhadap whistleblowing internal.

\section{Hasil Pengujian Hipotesis 2}

Tabel 4.15 Hasil Regresi Parsial Hipotesis Kedua

\begin{tabular}{lllll}
\hline Variabel Independen & $\mathrm{t}_{\text {hitung }}$ & $\mathrm{t}_{\text {tabel }}$ & $\mathrm{Sig}$ & Keterangan \\
\hline Tingkat KeseriusanKecurangan & -2.984 & 1.996 & 0.004 & Berpengaruh \\
\hline
\end{tabular}

Sumber : Data Olahan 2020

Hasil pengujian hipotesis kedua, dapat dilihat bahwa $t_{\text {hitung }}>t_{\text {tabel }}$ yaitu 2.954>-1.996 dan sig $\mathrm{t}(0.004)<0.05$ dengan demikian $\mathrm{H}_{02}$ ditolak dan Ha2 diterima. Maka dapat disimpulkan bahwa tingkat keseriusan kecurangan berpengaruh negatif terhadap niat melakukan whistleblowing. Ini dapat membuktikan bahwa pegawai organisasi perangkat daerah (OPD) di Kabupaten KuantanSingingi akan cenderung melaporkan kecurangan yang terjadi jika

* Corresponding author's e-mail: yesimutia@gmail.com

http://openjournal.unpam.ac.id/index.php/JABI 
menimbulkan kerugian keuangan yang signifikan, atau ia justru akan melaporkan kecurangan yang memberikan dampak negatif pada lebih dari satu orang. Logikanya, jika seseorang melihat dampak yang sangat negatif dari sebuah pelanggaran yang ada di sekitarnya, maka kemungkinan orang tersebut untuk melakukan pelaporan juga menjadi tinggi. Jika masalah dianggap serius, individu tersebut berkemungkinan akan melakukan pelaporan untuk meminimalisir kemungkinan kerugian yang diterima organisasi dan kerugian yang mungkin juga melibatkan diri individu tersebut. Hasil penelitian ini konsisten dengan penelitian Odiatma (2017) yang menemukan Tingkat Keseriusan Kesalahan berpengaruh terhadap niat melakukan Whistleblowing.

\section{Hasil Pengujian Hipotesis 3}

Tabel 4.16 Hasil Regresi Parsial Hipotesis Ketiga

\begin{tabular}{lllll}
\hline Variabel Independen & $t_{\text {hitung }}$ & $t_{\text {tabel }}$ & Sig & Keterangan \\
\hline Komitmen Organisasi & 2.439 & 1.996 & 0.017 & Berpengaruh \\
\hline Sumber : Data Olahan 2020 & & &
\end{tabular}

Hasil pengujian hipotesis ketiga, dapat dilihat bahwa $t_{\text {hitung }}>t_{\text {tabel }}$ yaitu 2.439> 1.995 dan sig $\mathrm{t}(0.017)<0.05$ dengan demikian $\mathrm{H}_{03}$ ditolak dan Ha3 diterima. Maka dapat disimpulkan bahwa komitmen organisasi berpengaruh terhadap niat melakukan whistleblowing. Karyawan yang memiliki komitmen organisasi yang tinggi di dalam dirinya akan timbul rasa memiliki organisasi (sense of belonging) yang tinggi sehingga ia tidak akan merasa ragu untuk melakukan whistle-blowing karena ia yakin tindakan tersebut akan melindungi perusahaan dari kehancuran (Kuryanto, 2011). Ini dapat membuktikan bahwa pegawai organisasi perangkat daerah (OPD) Kabupaten Kampar yang memiliki komitmen organisasi yang tinggi di dalam dirinya akan timbul rasa memiliki organisasi (sense of belonging) yang tinggi sehingga ia tidak akan merasa ragu untuk melakukan whistle-blowing karena ia yakin tindakan tersebut akan melindungi organisasi dari kehancuran.Hasil penelitian ini konsisten dengan penelitian yang dilakukan Setiawati dan Sari (2016) menyatakan bahwa komitmen organisasi berpengaruh terhadap niat whistle-blowing.

\section{Hasil Pengujian Hipotesis 4}

Tabel 4.17 Hasil Regresi Parsial Hipotesis Keempat

\begin{tabular}{lllll}
\hline Variabel Independen & $\mathrm{t}_{\text {hitung }}$ & $\mathrm{t}_{\text {tabel }}$ & $\mathrm{Sig}$ & Keterangan \\
\hline Komitmen Profesional & 2.589 & 1.996 & 0.012 & Berpengaruh \\
\hline
\end{tabular}

Sumber : Data Olahan 2020

* Corresponding author's e-mail: yesimutia@gmail.com http://openjournal.unpam.ac.id/index.php/JABI 
Hasil pengujian hipotesis keempat, dapat dilihat bahwa $t_{\text {hitung }}>t_{\text {tabel }}$ yaitu 2.589> 1.996 dan sig $\mathrm{t}(0.012)<0.05$ dengan demikian $\mathrm{H}_{04}$ ditolak dan Ha4 diterima. Maka dapat disimpulkan bahwa komitmen professional berpengaruh terhadap niat melakukan whistleblowing. Komitmen profesi menunjukan adanya kesukaan yang dibentuk oleh seseorang terhadap profesinya (Aranya et al., 1982 dalam Elias, 2008). Seorang yang berkomitmen profesi memercayai dan menerima tujuan profesi serta berkeinginan untuk melakukan berbagai upaya demi mencapai tujuan profesi tanpa diminta. Tingkat komitmen profesional mungkin merupakan refleksi hubungan staf atau karyawan dengan lingkungan industri profesional. Berkomitmen terhadap profesi berarti berkeyakinan bahwa profesi yang dilakukan memiliki dan memberikan hal yang baik bagi diri seseorang. Hal ini pun muncul berdasarkan pertimbangan seseorang atas apa yang dinilainya baik dan benar (Shaub et a, 1993). Hasil penelitian ini konsisten dengan penelitian Amalia (2018) yang menyatakan bahwa komitmen profesional berpengaruh terhadap whistleblowing.

\section{KESIMPULAN DAN SARAN}

\section{Kesimpulan}

Dari hasil evaluasi model penelitian dan pengujian hipotesis yang dilakukan dalam penelitian ini, maka menghasilkan beberapa kesimpulan yaitu sebagai berikut :

1) Hasil pengujian hipotesis pertama menunjukan bahwa personal cost berpengaruh terhadap niat melakukan whistleblowing. Semakin besar persepsi personal cost seseorang maka akan mempengaruhi untuk melakukan tindakan whistleblowing.

2) Hasil pengujian hipotesis kedua menunjukan bahwa tingkat keseriusan kecurangan berpengaruh terhadap niat melakukan whistleblowing. Semakin serius sebuah kecurangan maka akan semakin tinggi pula niat pegawai yang mengetahuiya untuk melakukan tindakan whistleblowing.

3) Hasil pengujian hipotesis ketiga menunjukan bahwa komitmen organisasi berpengaruh terhadap niat melakukan whistleblowing. Hasil penelitian ini menunjukkan bahwa sebuah komitmen organisasi yang tinggi akan menimbulkan rasa memiliki organisasi yang tinggi pula, sehingga ia tidak akan merasa ragu untuk melakukan whistleblowing.

4) Hasil pengujian hipotesis keempat menunjukan bahwa komitmen professional berpengaruh terhadap niat melakukan whistleblowing. Semakin tinggi suatu komitmen terhadap profesinya maka akan semakin tinggi pula niat pegawai Saran yang mengetahuiya untuk melakukan tindakan whistleblowing.

Penelitian ini masih memiliki keterbatasan, oleh karena itu :

* Corresponding author's e-mail: yesimutia@gmail.com http://openjournal.unpam.ac.id/index.php/JABI 
Jurnal Akuntansi Berkelanjutan Indonesia - Vol. 3, No. 3, Sep 2020 - Agustin, Basri \& Darlis

1) Penggunaan selain metode survey (kuisioner) seperti motede interview dapat digunakan untuk mendapatkan komunikasi dua arah dengan subjek dan mendapatkan kejujuran jawaban subjek.

2) Untuk penelitian selanjutnya agar ruang lingkup sampel diperluas seperti di kota-kota besar di Pulau Sumatera lainnya dan sebaiknya sampel yang digunakan lebih banyak sehingga mungkin saja hasilnya berbeda.

3) Untuk penelitian selanjutnya, diharapkan mampu memberikan implikasi baik secara teoritis maupun praktis. Implikasi teoritis digunakan untuk menambah literatur khususnya yang menyangkut niat melakukan whistleblowing, implikasi praktis bertujuan untuk bahan pertimbangan pengambilan keputusan yang diharapkan dapat meningkatkan seseorang dalam melakukan tindakan whistleblowing.

\section{DAFTAR PUSTAKA}

Bagustianto, R., \& Nurkholis. (2015). Faktor-Faktor yang Mempengaruhi Niat Pegawai Negeri Sipil (PNS) Untuk Melakukan Tindakan Whistleblowing (tudi pada PNS BPK RI). Surabaya.

Davitri, A. N. (2013). Pengaruh Pertimbangan Etis dan Komponen Perilaku Terencana Pada Niat Whistleblowing Internal Dengan Locus OfControl Sebagai Variabel Pemoderasi. Yogyakarta.

Evanti, D. A. \& Ahmad. (2015). Analisis Faktor-Faktor Yang Mempengaruhi Intensi Auditor Untuk Melakukan Tindakan Whistleblowing. DKI Jakarta. Doctoral Dissertation Binus

Hanif, R. A. \& Fajar. (2017). Pengaruh Personal Cost Of Reporting, Status Wrong Doer, dan Tingkat Keseriusan Kesalahan Tehadap Whistleblowing Intention. Jurnal Akuntansi Keuangan dan Bisnis Vol. 10, No. 1, Mei 2017, 11-20.

Husniati, Hj. S. (2017). Faktor-Faktor Yang Mempengaruhi Intensi Untuk Melakukan Whistleblowing Internal. Rokan Hulu.

Dimas, A. Y. (2015). Pengaruh Orientasi Etika, Komitmen Profesional, dan Sensitivitas Etis Terhadap Whistleblowing. Yogyakarta.

Septianti, W. (2013). Pengaruh Faktor Organisasional, Individual, Situasional, dan Demografis Terhadap Niat Melakukan Whistleblowing Internal. Manado: Simposium Nasional Akuntansi

Setiawati, L. P. M. M. R. S. (2016). Profesionalisme, Komitmen Organisasi, Intensitas Moral dan Tindakan Akuntan Melakukan Whistleblowing. EJurnal Akuntansi Universitas Udayana.

* Corresponding author's e-mail: yesimutia@gmail.com

http://openjournal.unpam.ac.id/index.php/JABI 